\title{
Socioeconomic Impacts of the COVID-19 Lockdown on the Mental Health and Life Satisfaction of the Japanese Population
}

\author{
Daichi Sugawara $^{1}$ (D) Akihiro Masuyama² $\cdot$ Takahiro Kubo $^{3}$
}

Accepted: 15 December 2020 /Published online: 2 December 2021

(c) The Author(s), under exclusive licence to Springer Science+Business Media, LLC, part of Springer Nature 2021

\begin{abstract}
COVID-19 has been a global challenge ever since its emergence, with reports suggesting negative effects on the mental health and well-being of people. We investigated the associations of the socioeconomic changes driven by the pandemic, illness, well-being, and fear of COVID-19 in Japan. Totally, 565 Japanese individuals completed an online survey, including questions on their self-restraint and changing incomes, and the Fear of COVID19 Scale; Depression, Anxiety, Stress Scale; and present, past, and future life satisfaction scale. Analysis using structural equation models revealed that refraining from going out was a predictor of illness due to the fear of COVID-19. Decreased income predicted increased illness, but was not due to fear of COVID-19. These results suggested that the interaction between decreased time outside and increased fear of COVID-19 could affect illness. Our study suggests the role of fear of COVID-19 during pandemic and the socioeconomic impacts on mental health.
\end{abstract}

Keywords COVID-19 $\cdot$ Changing income $\cdot$ Self-restraint $\cdot$ Fear of COVID-19 scale · Mental health

\section{Background}

Since its emergence, the coronavirus disease (COVID-19), caused by the severe acute respiratory syndrome coronavirus 2 (SARS-CoV-2), has created many challenges globally, and continues to do so till date. According to a report by the World Health Organization (WHO), the number of individuals with a confirmed SARS-CoV-2 infection stood at almost ten million on June 28, 2020 (World Health Organization [WHO], 2020). Though the increasing number of infected individuals has been moderated, compared to early 2020 , the ongoing quarantines and fear of COVID-19 remain worldwide challenges. Although

Daichi Sugawara

sugawara@human.tsukuba.ac.jp

1 Faculty of Human Sciences, University of Tsukuba, Tsukuba City, Tennodai 305-8752, Japan

2 Faculty of Psychology, Iryo Sosei University, Fukushima, Japan

3 Faculty of Human Sciences, University of Tsukuba, 112-0012 Bunkyo-ku, Japan 
Japan has witnessed less damage by the COVID-19 pandemic than Europe, the people in Japan are nonetheless suffering from social isolation and the socioeconomic impacts of the pandemic. Nicola et al. (2020) found through a multidimensional review that socioeconomic crises had been created by the pandemic and suggested the importance of long-term planning to re-energize societies and economies globally.

An extensive array of literature has pointed out the effects of quarantine and self-isolation on mental health (Greenberg et al., 2020; Qiu, et al., 2020; Rajkumar, 2020; Torales et al., 2020). In Japan, Sasaki et al. (2020) revealed that worsening mental health was associated with psychological distress, worry, and job instability during the COVID-19 pandemic. Shigemura et al. (2020) also pointed out the impacts of COVID-19 on psychological well-being and mental health, and the vulnerability of these two factors in the general population. These reports suggest the importance of research studies investigating the effects of the COVID-19 pandemic on the mental health and well-being of individuals, as well as those who are working to establish treatments.

Given the implications that mental health and stress levels have worsened and people's lives are rapidly changing, life satisfaction - a cognitive appraisal of an individual's own life, which is involved with subjective well-being (Diener, 1984; Shin \& Johnson, 1978)— also needs to be investigated in relation to the COVID-19 pandemic. It can be postulated that the pandemic will impact the psychological aspects of individuals, along with social, economic, and daily life changes. Main et al. (2011) revealed that during the Severe Acute Respiratory Syndrome (SARS) pandemic which occurred between 2002 and 2004, lower life satisfaction was associated with the worsening of mental health, driven by the outbreak. Zhang et al. (2020) found that temporal life satisfaction in the Chinese population was associated with health problems in the early period of the COVID-19 outbreak (in late February 2020). The concept of life satisfaction has been well known to encompass satisfaction for the past and future in addition to the present (Carrillo et al., 2018; Pavot et al., 1998). However, these aspects remain unclear with regard to the current pandemic. Indeed, life satisfaction for the future is known to be associated with anticipation of better outcomes, including those for mental and physical health, and socioeconomic factors (Lang et al., 2013; Sirgy et al., 2019). The re-energizing of mental health under the pandemic situation is clearly needed, along with investigations on life satisfaction for the future and the relationship between mental health and life changes driven by the current pandemic.

The fear of COVID-19 has recently received attention as a psychological factor related to the outbreak. Ever since Ahorsu et al. (2020) developed the Fear of COVID-19 Scale (FCV-19 S), it has been translated and validated in many languages: Arabic (Alyami et al., 2020), Bangla (Sakib et al., 2020), Hebrew (Bitan et al., 2020), Italian (Soraci et al., 2020), Russian (Reznik et al., 2020), Spanish (Huarcaya-Victoria et al., 2020), Turkish (Satici et al., 2020), along with the original Persian (Ahorsu et al., 2020) and English version (Winter et al., 2020). In addition to the translation and validation of the FCV-19 S, these research studies investigated its association with other mental health questionnaires, suggesting that worsening mental health was related to fear of COVID-19. Considering that the pandemic has continued until now, the fear of COVID-19 seems to be an important psychological factor in research on the current mental health of the global population.

Furthermore, as mentioned above, it is important to assess socioeconomic influences as a result of quarantine for the pandemic, even in the context of mental health. Extensive literature has already shown that socioeconomic factors are associated with mental health, psychological aspects, and subjective well-being (Moor et al., 2017; Read et al., 2016), suggesting a link between worsening mental health-related outcomes and lower social activity and economic status. During the current pandemic, it was found that the time of 
going out was decreased in Japan, as a result of self-restricting behavior (Parady et al., 2020). Besides, Roy et al. (2020) revealed that the tendency of avoiding social contact was associated with anxiety during the pandemic, suggesting that self-restricting behavior is related to psychological and mental health aspects. Regarding economic factors, Cao et al. (2020) suggested that individuals with an unstable income showed higher anxiety about income, which strongly affected psychological distress. Taken together, previous studies investigated the understanding of changes in current social activity and economic status, and suggested that the time of going out and instability of income were related to mental health outcomes. However, the pathway from these socioeconomic changes to mental health-related outcomes still remain uncertain.

Thus, this study aimed to investigate the associations of socioeconomic changes driven by the pandemic, mental health, life satisfaction (past, present, and future), and fear of COVID-19 in Japan. Furthermore, based on the number of studies that analyzed socioeconomic variables related to illness and/or well-being due to psychological variables using a structural model (e.g., Leversen et al., 2012; Obrien et al., 2012), we also used a structural model to explain illness and well-being during the COVID-19 pandemic. Specifically, the assumption that socioeconomic changes involving self-restraint and reduction in income are related to psychological distress and life satisfaction due to fear of COVID-19, is tested to clearly reveal the influence of these socioeconomic changes during the pandemic. We hypothesized that the reduced income and time of going out had an effect on illness (depression, anxiety, and stress), as well and on well-being (life satisfaction for present, past, and future), mediated by fear of COVID-19. Overall, this study aimed to provide insights into how the COVID-19 pandemic has affected both the illness and well-being of the general population of Japan.

\section{Methods}

\section{Participants and Procedure}

In total, 565 Japanese individuals (315 men, 55.75\%; 250 women, 44.25\%) participated in this study through a web survey hosted by Questant (a web research services company targeting the Japanese), between July 13 and July 24, 2020. Ethical considerations (e.g., that they could stop responding midway through the survey whenever they chose, and that they were free to participate in the survey) were also displayed on the web survey screen. Participants took approximately 15 min to complete the survey.

The mean age of the participants was 46.67 years (standard deviation $=13.19$; range $=$ 18-87). At the time of the survey, there were approximately 300,000 people infected with SARS-CoV-2 in Japan, and approximately 1,000 COVID-19-related deaths. A nationwide state of emergency was declared on April 16, 2020, the lifting of which was announced on May 25, 2020.

\section{Measures}

\section{Demographic Variables}

Participants were asked to indicate their age and type of job, and to provide responses to the following demographic items: self-restraint, assessed on a 3-point scale consisting of 
"time of going out was decreased in the last month," "time of going out was the same as before in the last month," and "time of going out was increased in the last month"; changing income, assessed on a 5-point scale ranging from "largely decreased" (1 point) to "largely increased" (5 point). The infection status of the participants, their relatives, and neighborhood was also assessed. The response choice "Not willing to answer" was included for all items.

\section{Fear of COVID-19 Scale}

The Japanese version of the FCV-19 S (FCV-19 S-J), validated by Masuyama et al. (2020), was used to assess the fear of COVID-19. FCV-19 S-J consists of the seven items of the original FCV-19 S, but is divided into two subscales: emotional responses (items 1, 2, 4, and 5; e.g., I am most afraid of coronavirus-19) and physiological responses (items 3, 6, and 7; e.g., My heart races or palpitates when I think about getting coronavirus-19). Masuyama et al. reported that the Japanese version of the FCV-19 S has high internal consistency $(\alpha>0.80)$. Participants respond to each item on a 5-point scale ranging from "strongly disagree" (1 point) to "strongly agree" (5 points). A higher score on each subscale indicates a greater fear of COVID-19. The $\alpha$ coefficients of the seven items in this study were 0.83 .

\section{Depression Anxiety Stress Scale}

The Japanese version Depression Anxiety Stress Scales (DASS; Lovibond \& Lovibond, 1995), originally developed by Antony et al. (1998), was used to assess multiple aspects of mental health. This consists of 21 of the original DASS items divided into three subscales: depression (e.g., I couldn't seem to experience any positive feeling at all), anxiety (e.g., I felt I was close to panic), and stress (e.g., I found it hard to wind down) (7 items in each subscale). Participants responded to each item on a 4-point scale ranging from "did not apply to me at all" ( 0 points) to "applied to me very much, or most of the time" ( 3 points). The three factors showed high internal consistency (depression: $\alpha=0.91$; anxiety: $\alpha=0.92$; stress: $\alpha=0.92$ ).

\section{Present, Past, and Future Life Satisfaction}

The Present, Past, and Future Life Satisfaction Scale (Prenda \& Lachman, 2001) was used to assess multiple aspects of mental health. This scale consists of three items (present, past, and future life satisfaction, with one item for each, that is, "How would you rate your life overall these days?"), with participants responding to each item on a 11-point scale ranging from "worst" (0 points) to "best" (10 points). The Japanese version of this scale has been used in large-scale surveys of people in Japan (e.g., Ryff et al., 2018) and has high reliability and validity. Life satisfaction for the present, past, and future was moderately or more positively correlated $(r=.39-.72, p<.01)$.

\section{Research Ethics}

This study was approved by the local research ethics committee of the first author's affiliation. The study was conducted on a voluntary basis, on the part of the participants. Personal information, such as respondents' personal names and addresses, was not asked for in this study. 
Table 1 FCV-19 S-J factor loading, mean values, standard deviation, skewness, and kurtosis

\begin{tabular}{|c|c|c|c|c|c|c|}
\hline \multicolumn{2}{|c|}{ Item } & Loading & $M$ & $S D$ & Skewness & Kurtosis \\
\hline \multicolumn{7}{|c|}{ F1: Physiological response $(\alpha=0.89, \omega=0.89)$} \\
\hline 7 & $\begin{array}{l}\text { My heart races or palpitates when I think about getting } \\
\text { coronavirus- } 19 \text {. }\end{array}$ & 0.94 & 2.03 & 1.06 & 0.72 & -0.35 \\
\hline 6 & $\begin{array}{l}\text { I cannot sleep because I'm worrying about getting corona- } \\
\text { virus-19. }\end{array}$ & 0.85 & 2.12 & 1.10 & 0.64 & -0.49 \\
\hline 3 & $\begin{array}{l}\text { My hands become clammy when I think about coronavi- } \\
\text { rus- } 19 \text {. }\end{array}$ & 0.79 & 1.95 & 1.03 & 0.87 & 0.08 \\
\hline \multicolumn{7}{|c|}{ F2: Emotional response $(\alpha=0.82, \omega=0.83)$} \\
\hline 1 & I am most afraid of coronavirus- 19. & 0.91 & 4.05 & 0.97 & -1.06 & 0.79 \\
\hline 2 & It makes me uncomfortable to think about coronavirus- 19 . & 0.71 & 4.00 & 0.98 & -1.02 & 0.83 \\
\hline 4 & I am afraid of losing my life because of coronavirus- 19. & 0.74 & 3.52 & 1.18 & -0.53 & -0.60 \\
\hline 5 & $\begin{array}{l}\text { When watching news and stories about coronavirus-19 on } \\
\text { social media, I become nervous or anxious. }\end{array}$ & 0.47 & 3.11 & 1.16 & -0.24 & -0.82 \\
\hline
\end{tabular}

The inter factor correlation between the first and second factors was $r=.37$

Table 2 Model and model fit of the FCV-19 S-J compared in this study

\begin{tabular}{llllllll}
\hline Model & $\chi 2 / \mathrm{df}$ & df & $p$ value & GFI & CFI & RMSEA & AIC \\
\hline 1. One-factor model & 739.602 & 14 & 0.000 & 0.689 & 0.638 & 0.303 & 767.602 \\
2. Two-factor model & 239.314 & 14 & 0.000 & 0.902 & 0.888 & 0.169 & 267.314 \\
3. Higher-one factor model & 227.980 & 13 & 0.000 & 0.902 & 0.893 & 0.171 & 257.980 \\
4. Bifactor model & 15.970 & 6 & 0.014 & 0.992 & 0.995 & 0.054 & 59.970 \\
\hline
\end{tabular}

FCV-19 S-J, Japanese version of Fear of COVID-19 Scale; $\chi 2$, chi-squared; df, degrees of freedom; GFI, Goodness of fit index; CFI, Comparative fit index; RMSEA, Root mean square error of approximation; AIC, Akaike information criterion

\section{Results}

\section{Model Comparison of the Confirmatory Factor Analysis of FCV-19 S-J}

Since, the FCV-19 S-J had previously been used only on adolescent populations (Masuyama et al., 2020), we tested its validity among the general Japanese population. The means and standard deviations of the responses to the seven FCV-19 S-J items are shown in Table 1. Since there was no significant bias in the distribution of scores, all seven items were included in the analysis. In contrast to Ahorsu et al. (2020), who reported the results of a one-factor model with the seven items of the FCV-19 S loaded on one factor, Masuyama et al. (2020) found a bi-factor model including emotional and physiological responses in the Japanese version of the FCV-19 S. In addition to these results, we newly assumed a higher-order factor model in which two factors were loaded on one higher-order factor. Thus, in this study, four constructive models, that is, one-factor, two-factor, bi-factor, and higher-order factor models, were tested. Based on the goodness-of-fit results for these models (Table 2), the bi-factor model had the best goodness of fit when considering the Akaike information criterion (AIC) suitable for comparison between the models (AIC = 59.970). This is consistent with the results of Masuyama et al. (2020). The goodness of fit of this 
study was consistent with the criterion (Hu \& Benter, 1998) that states that the comparative fit index (CFI) should be above 0.95 and the root mean square error of approximation (RMSEA) should be below 0.06 . On the basis of our results, as well as a previous study (Masuyama et al., 2020), we adopted the bi-factor model for the FCV-19 S. Hence, both factors showed high internal consistency (emotional responses: $\alpha=0.89, \omega=0.89$; physiological responses: $\alpha=0.82, \omega=0.83$ ).

\section{Influence of Self-restraint and Changing Income}

We examined the differences in self-restraint and changing income due to fear of COVID19. The response rates for these two items are shown in Table 3. For self-restraint, since the number of responses for "time of going out was increased in the last month" was very few $(n=31 ; 5.50 \%)$, we only conducted $t$-tests on the responses for "time of going out was decreased in the last month" and "time of going out was the same as before in the last month" on the FCV-19 S-J, DASS, and the life satisfaction scale (Table 4). Significant differences were observed in the mean numbers of responses for the FCV-19 S-J, emotional responses, physiological responses, and depression, anxiety, and stress $(t(525)=$ $2.35-4.64, p=.000-0.019, d=0.21-0.39)$. This suggested that people who spent less time outside, compared to their usual life, had a higher emotional and physiological response to the COVID-19 pandemic and had higher levels of depression, anxiety, and stress. However, no significant differences were observed in past, present, and future life satisfaction.

Regarding changes in income, we conducted one-way analysis of variance (ANOVA) for the "largely decreased," "slightly decreased," and "almost the same" groups only, on the FCV-19 S-J, DASS, and life satisfaction scale (Table 5). We excluded the responses of "slightly increased" and "largely increased" because of a very small number of responses on these options $(n=10(1.77 \%)$ and $2(0.35 \%)$, respectively). Results indicated a significant main effect of income $\left(F(3,543)=5.44-20.25\right.$ and $\left.\eta_{\mathrm{p}}^{2}=0.017-0.070\right)$. Then, contrast analysis between the total score of the FCV-19 S-J and each subscale score showed that emotional and physiological responses was higher in the "largely decreased" group than in the "almost the same" group $(p<.05)$, whereas, scores for present and future life

Table 3 Rate of responses for self-restraint and changing income

\begin{tabular}{lll}
\hline & \multicolumn{2}{l}{ Self-restraint } \\
\cline { 2 - 3 } & $n$ & $\%$ \\
\hline Decreased in last month & 226 & 40.00 \\
Same as before in last month & 301 & 53.30 \\
Increased in last month & 31 & 5.50 \\
Not willing to answer & 7 & 1.20 \\
& Changing income & \\
Largely decreased & $n$ & $\%$ \\
Slightly decreased & 64 & 11.33 \\
Almost the same & 117 & 20.71 \\
Slightly increased & 361 & 63.89 \\
Largely increased & 10 & 1.77 \\
Not willing to answer & 2 & 0.35 \\
\hline
\end{tabular}


Table 4 The difference of self-restraint on FCV-19 S, DASS, and present, future, and past satisfaction of life

\begin{tabular}{|c|c|c|c|c|c|c|c|c|}
\hline & \multicolumn{2}{|c|}{$\begin{array}{l}\text { Decreased in last } \\
\text { month }\end{array}$} & \multicolumn{2}{|c|}{$\begin{array}{l}\text { Same as before } \\
\text { in last month }\end{array}$} & \multirow[t]{2}{*}{$d f$} & \multirow[t]{2}{*}{$t$} & \multirow[t]{2}{*}{$p$} & \multirow[t]{2}{*}{$d$} \\
\hline & $M$ & $S D$ & $M$ & $S D$ & & & & \\
\hline FCV & 21.83 & 5.09 & 19.86 & 5.12 & 486.20 & 4.37 & $<0.000^{* * *}$ & 0.38 \\
\hline Emotional responses & 15.47 & 3.37 & 14.09 & 3.43 & 489.22 & 4.64 & $<0.000^{* * *}$ & 0.39 \\
\hline Physiological responses & 6.35 & 2.82 & 5.78 & 2.74 & 476.68 & 2.35 & $0.019^{*}$ & 0.21 \\
\hline \multicolumn{9}{|l|}{ DASS } \\
\hline Depression & 11.85 & 5.30 & 10.35 & 4.49 & 437.47 & 3.42 & $0.001^{* *}$ & 0.31 \\
\hline Anxiety & 9.59 & 3.93 & 8.69 & 3.18 & 424.02 & 2.81 & $0.005^{* *}$ & 0.26 \\
\hline Stress & 11.46 & 4.73 & 9.80 & 3.86 & 425.85 & 4.29 & $<0.000^{* * *}$ & 0.39 \\
\hline Present satisfaction & 6.05 & 2.20 & 6.19 & 2.01 & 460.52 & -0.75 & 0.451 & -0.07 \\
\hline Future satisfaction & 6.46 & 2.36 & 6.39 & 2.26 & 473.84 & 0.39 & 0.698 & 0.03 \\
\hline Past satisfaction & 6.62 & 2.25 & 6.46 & 1.90 & 436.50 & 0.91 & 0.362 & 0.08 \\
\hline
\end{tabular}

FCV-19 S-J, Japanese version of Fear of COVID-19 Scale; DASS, Depression, Anxiety, Stress Scale; M, mean values; SD, standard deviation; t, t value; $d$, Cohen's d

$* p<.05, * * p<.01, * * * p<.001$

satisfaction were lower in the "largely decreased" group than in the "almost the same" group. For depression, anxiety, and stress, the mean numbers of "largely decreased" responses were higher than those of "slightly decreased" (depression, $d=0.49, p<.001$; anxiety, $d=0.27, p<.001$; stress, $d=0.23, p<.05)$ which in turn were higher than those of "almost the same" (depression, $d=0.23, p<.001$; anxiety, $d=0.30, p<.001$; stress, $d$ $=0.39, p<.05)$.

\section{Correlation Analysis}

We conducted correlation analyses for fear of COVID-19, depression, anxiety, and stress, life satisfaction (present, future, past), and age. Fear of COVID-19 had a significant positive correlation $(r s=0.36-0.42, p s<0.01)$ with the three subscales of the DASS (depression, anxiety, stress), and a marginally significant negative correlation with future life satisfaction $(r=-.07, p<.10)$. The three subscales of the DASS had significant negative correlations with present, future, and past life satisfaction $(r s=-.15--.38, p<.01)$. Age had a significant correlation with depression $(r=-.21, p<.05)$, stress $(r=-.16, p<.01)$, and present life satisfaction $(r=.17, p<.01)$, and a marginally significant correlation with fear of COVID-19 $(r=.05, p>.10)$.

\section{Mediation Effect of the Fear of COVID-19}

We hypothesized that the reduced income and time of going out had an effect on illness, and well-being, due to the fear of COVID-19. Therefore, we set up a causal model and examined the mediation effect of the fear of COVID-19, using structural equation modeling (Fig. 1). The scores of the three DASS factors were used as latent variables of illness, and the scores of life 


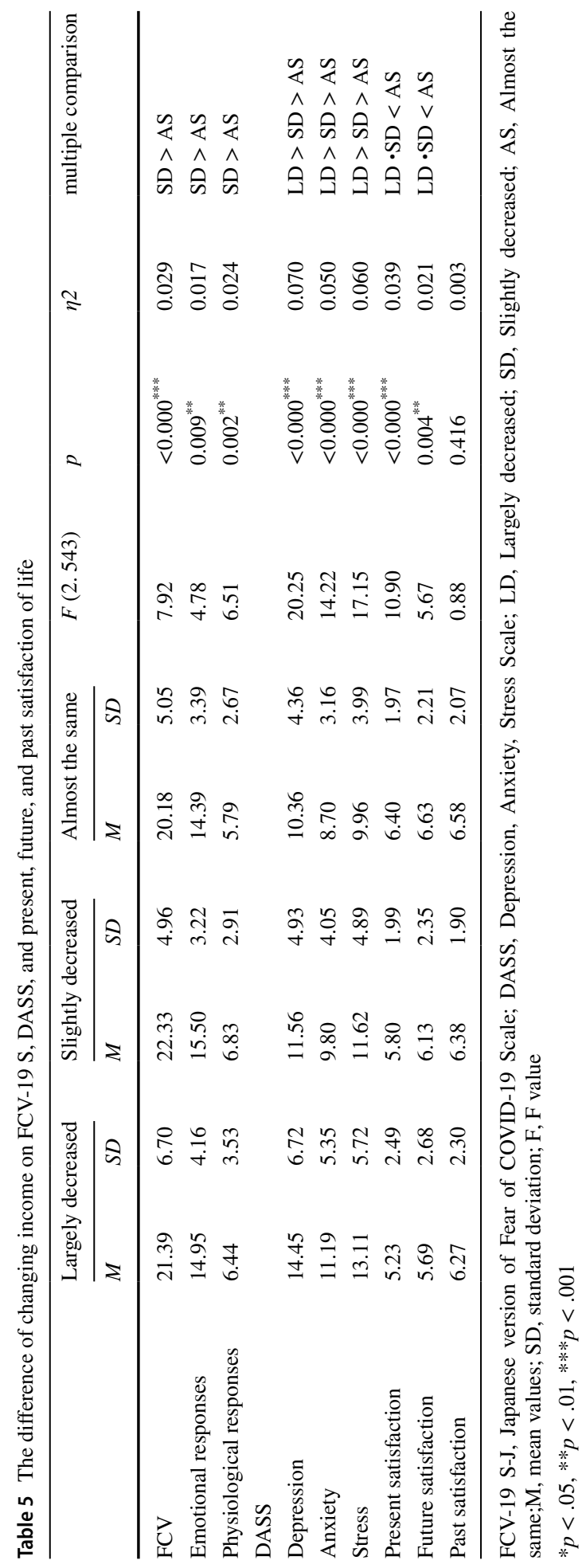




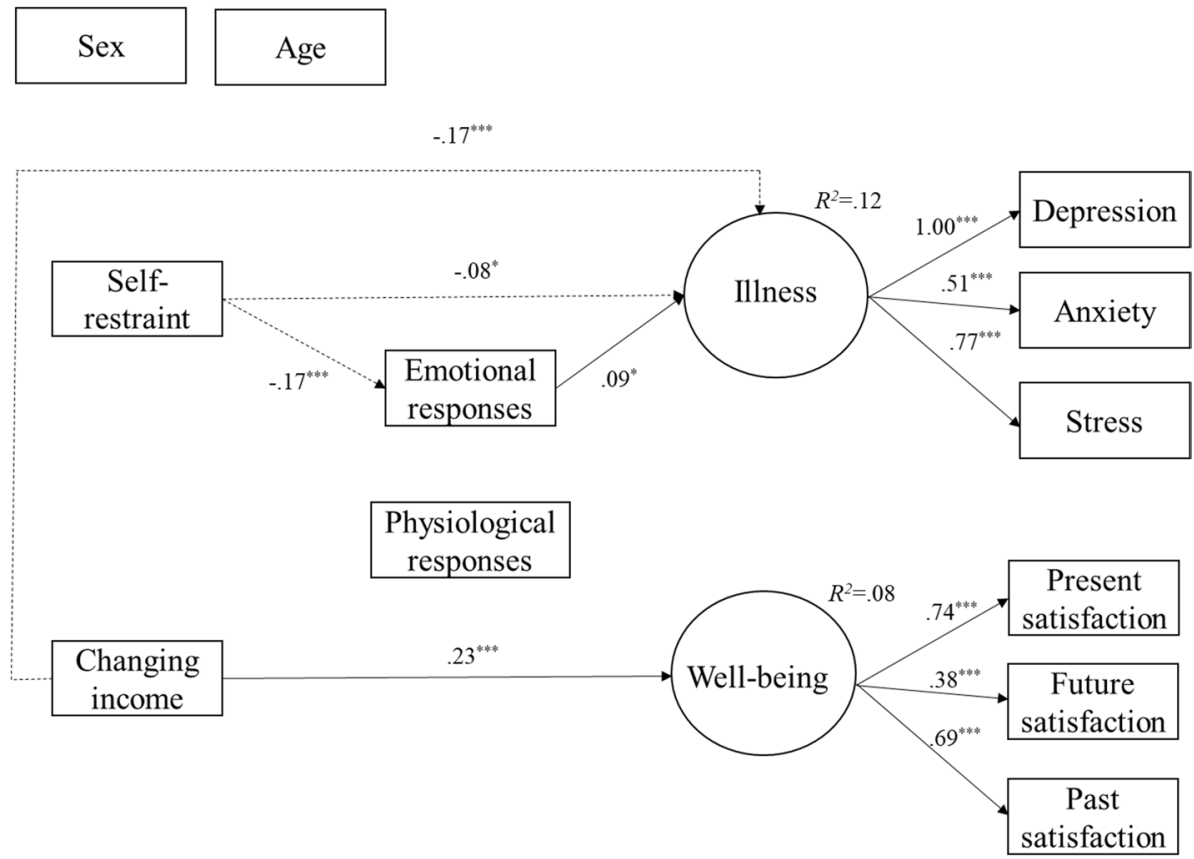

Fig. 1 Fear of COVID-19 mediated model of the self-restraint and changing income on mental health

satisfaction for the past, present, and future were used as latent variables of well-being. In the models examined in this study, we controlled for the effects of gender and age.

First, we examined the model for fear of COVID-19-mediated effects of reduced income and time of going outside on illness and well-being (Fig. 1). The model fit indices showed good estimates $\left(\chi^{2}=237.78, d f=37, p=.000, \mathrm{CFI}=0.913\right.$, GFI $=0.934$, RMSEA $=0.103$ ). Based on $\mathrm{Hu}$ and Benter (1998), the model fit was in the acceptable range (CFI $>0.900$, GFI $>0.900)$. The $\chi$-squared values were significant due to the influence of degrees of freedom.

In this model, the reduction in going outside was negatively associated with emotional responses $(\beta=-0.17, p<.001)$ and illness $(\beta=-0.08, p<.05)$. Changing income was negatively associated with illness $(\beta=-0.17, p<.001)$ and positively associated with well-being $(\beta=0.23, p<.001)$. Emotional responses were positively associated with illness $(\beta=0.09, p$ $<.05)$. The results suggested that decreased income led to a worsening of both psychological distress and life satisfaction.

Additionally, we examined whether each indirect effect was significant in this model, using a percentile bootstrapping method (sample $=5000$ ) according to the recommendations of Cheung and Lau (2008). The indirect effect (self-restraint to illness mediated emotional responses) was significant $(\beta=-0.16, p<.05)$. 


\section{Discussion}

This study investigated the associations among socioeconomic changes driven by the COVID-19 pandemic, illness, well-being, and fear of COVID-19 in the Japanese population. The results of the mediation analysis revealed that refraining from going out was a predictor of illness influenced by the fear of COVID-19. This suggests that the interaction of decreased time for going outside and increased fear of COVID-19 could affect the illness of the individual. Our results also suggest that reduced income may directly increase illness and decrease well-being, without the mediating effect of the fear of COVID-19. These results partially supported our hypothesis that socioeconomic changes (decreased time for going out and reduction of income) would predict the fear of COVID-19, and this relationship would be associated with greater illness and lower well-being.

Regarding self-restraint, we found that reduction of the time for going outside affected psychological illness, resulting in symptoms of depression, anxiety, and stress due to the mediating effect of the fear of COVID-19. Interestingly, people who tend to refrain more from going out and try harder to avoid infection, experience a greater fear of COVID-19, which further leads to greater psychological distress. This paradoxical result might be explained by the relationship of avoidance behavior and specific phobia in the context of psychopathology. Several theories and empirical research for specific phobia and anxiety reported that avoidance behavior plays a crucial role in maintaining fear and anxiety (Dymond \& Roche, 2009; Newman \& Llera, 2011; Rachman, 1994). According to the cognitive model proposed by Rachman (1984), overprediction of fear promotes avoidance behavior to prevent temporal stress. From this perspective, avoidance behavior serves as a safety behavior, and maintenance factor for long-term fear and anxiety. Thus, it can be implied that the overprediction of COVID-19 infection promotes avoidance behavior in the form of self-restraint; however, such behavior leads to an increase in fear, resulting in psychological distress. As further explanation, an increase in the fear of COVID19 among those showing greater self-restraint could be the result of gaining information about COVID-19 from social media while staying home. Indeed, Mejia et al. (2020) suggested that viewing television content about COVID-19 and the ensuing pandemic might increase fear of COVID-19. Combined with our results, we can assume that the increased time for watching social media instead of the time for going out was associated with fear of COVID-19 and this interaction led to worse illness.

Regarding change in income, our results revealed that reduced income directly affected well-being, including life satisfaction toward the past, present, and future. Since, a decrease in income leads to an unstable lifestyle in general, it might predict deteriorations in any of the indices of well-being. Indeed, Boyce et al. (2010) showed that household income predicted current life satisfaction. Furthermore, Dumludag (2013) found the association of current income with past evaluation and future prediction toward life, suggesting that individuals with current low income negatively evaluated their past and future. Current negative and stressful life events were found to influence negative appraisal toward life satisfaction (Mehlsen et al., 2005). Given these underlying cognitive processes involved in the evaluation of life satisfaction, the results of this study reflected a negative cognitive reappraisal by the participants toward life, including past, current, and future, with the pandemic as the stressor. To evaluate well-being, we investigated life satisfaction alone. Several studies considered other aspects of well-being, such as quality of life (Alyami et al., 2020), hope (Yıldırım \& Arslan, 2020), and work satisfaction (Labrague \& De los Santos, 2020). Although our study was the first to investigate well-being during the current 
pandemic among the Japanese population, further studies are needed to reveal the influence of the pandemic on multiple aspects of psychological well-being in Japan.

Regarding the socioeconomic impacts on well-being and illness, the mediating effect of the fear of COVID-19 was investigated in this study. As we assumed, the results of structural modeling showed that emotional responses, as assessed by the FCV-19 S-J, had a mediating effect on self-restraint. However, such effects were not found for physiological responses. Considering the stronger factor load of depression, compared to anxiety and stress, the sample of this study could be strongly suffering from a depressed mood rather than anxiety-related somatic problems. As Masuyama et al. (2020) pointed out, individuals with higher physiological responses on the FCV-19 S-J were possibly suffering from severe symptoms of fear; thus, the sample of this study could be interpreted as having a moderate or mild fear of COVID-19, overall.

Subsequently, we conducted a confirmatory factor analysis on the Japanese version of the FCV-19 S. Consistent with the results of a previous study that validated the FCV-19 S on Japanese adolescents (Masuyama et al., 2020), our results showed that the bi-factor model had better fitness than the one-factor and two-factor models, suggesting that FCV19 S-J has bi-factors (viz., emotional response and physiological response) for both adult and adolescent samples. However, although some studies (Reznik et al., 2020; Chi et al., 2020) using FCV-19 S to evaluate the fear of COVID-19 have supported the bi-factor construction of the scale, other majority studies, including the original study on the Persian population (Ahorsu et al., 2020), have reported a one-factor construction (e.g., Satici et al., 2020; Soraci et al., 2020). According to a previous study that validated the Japanese FCV$19 \mathrm{~S}$ version (Masuyama et al., 2020), there is a possibility that the constructive distinction of FCV-19 S might be due to the differential status of infection in each country and/or cultural differences regarding fear. The confirmed cases of COVID-19 in Japan, in which the survey was carried out, were less than other countries (WHO, 2020). This lower level of damage caused by COVID-19 implied that few individuals experienced some of the fear responses (clammy hands, sleep disturbance, and heart palpitation) included in the physiological responses in our results; this may have led to divided bi-factors. There is also a possibility that the concept of fear and its response had cultural variation; extensive literature has shown the cultural variation in emotion (for review, see Meskita \& Frjuda, 1992).

\section{Limitations}

There are several limitations to this study, First, we investigated the socioeconomic impacts using limited variables. Generally, the socioeconomic variables used in research are as follows: employment status, partner and/or family, income rank, religion, and education. In addition to limited measures of illness and well-being, there is the possibility of other variables confounding these factors. Second, our data for the socioeconomic variables was obtained from self-reports alone. A previous study which measured socioeconomic variables carried out their survey as a national representative panel study (Cheung \& Lucas, 2015), and obtained objective income data. Moreover, regarding self-restraint, some studies used mobility data obtained from the mobile phones of participants (Hsiehchen et al., 2020). Here, our data lack of objectivity is revealed, compared to these studies. Further research is needed to explore the effects of the pandemic on socioeconomic status, using more objective data. For example, it is necessary to measure actual personal income before the spread of coronavirus infection and how much income was actually reduced after the spread. Moreover, as the data for this study were gathered from a survey conducted in July 
2020, the results may vary depending on the time at which future surveys are conducted. Thus, for future studies, the psychological effects of COVID-19 pandemic need to be investigated by integrating the infection status at specific times in each region.

\section{Conclusions}

We explored the associations of changing lifestyles, mental health (illness and well-being), and fear of COVID-19 during the current pandemic, in the Japanese population. The results showed that emotional fear of COVID-19 influenced the effects of reduced time for going outside on illness, and a direct effect of reduced income on well-being. Our results indicate the role of fear of COVID-19 during pandemic and the socioeconomic impacts on mental health.

Acknowledgements We would like to thank Editage (www.editage.com) for English language editing.

Funding This study was partly supported by Research Support Program to Apply the Wisdom of the University to tackle COVID -19 Related Emergency Problems, University of Tsukuba.

\section{Declarations}

Conflict of Interest Author DS, Author MA and Author KT declare that they have no conflict of interest.

Informed Consent All procedures followed were in accordance with the ethical standards of the responsible committee on human experimentation (institutional and national) and with the Helsinki Declaration of 1975, as revised in 2000 (5). Informed consent was obtained from all patients for being included in the study.

Ethical Approval This research was approved by the research ethics committee of the University of Tsukuba, Japan.

\section{References}

Ahorsu, D. K., Lin, C. Y., Imani, V., Saffari, M., Griffiths, M. D., \& Pakpour, A. H. (2020). The Fear of COVID-19 Scale: Development and initial validation. International Journal of Mental Health and Addiction, 1-9. https://doi.org/10.1007/s11469-020-00270-8

Antony, M. M., Bieling, P. J., Cox, B. J., Enns, M. W., \& Swinson, R. P. (1998). Psychometric properties of the 42-item and 21-item versions of the Depression Anxiety Stress Scales in clinical groups and a community sample. Psychological Assessment, 10(2), 176-181

Alyami, M., De Albuquerque, J. V., Krägeloh, C. U., Alyami, H., \& Henning, M. A. (2020). Effects of Fear of COVID-19 on mental well-being and quality of life: A path analysis. (PREPRINT (Version 1) available at Research Square). https://doi.org/10.21203/rs.3.rs-59161/v1

Alyami, M., Henning, M., Krägeloh, C. U., \& Alyami, H. (2020). Psychometric evaluation of the Arabic version of the Fear of COVID-19 Scale. International Journal of Mental Health and Addiction. https:// doi.org/10.1007/s11469-020-00316-X

Bitan, D. T., Grossman-Giron, A., Bloch, Y., Mayer, Y., Shiffman, N., \& Mendlovic, S. (2020). Fear of COVID-19 scale: Psychometric characteristics, reliability and validity in the Israeli population. Psychiatry Research, 289, 113100

Boyce, C. J., Brown, G. D., \& Moore, S. C. (2010). Money and happiness: Rank of income, not income, affects life satisfaction. Psychological Science, 21(4), 471-475

Carrillo, A., Etchemendy, E., \& Baños, R. M. (2018). Past, present, and future life satisfaction: The role of age, positive and negative mood. Current Psychology. https://doi.org/10.1007/s12144-018-9981-9 
Cao, W., Fang, Z., Hou, G., Han, M., Xu, X., Dong, J., \& Zheng, J. (2020). The psychological impact of the COVID-19 epidemic on college students in China. Psychiatry Research, 287(January). https://doi.org/ 10.1016/j.psychres.2020.112934

Chi, X., Chen, S., Chen, Y., Chen, D., Yu, Q., Guo, T. ... Zou, L. (2020). Psychometric evaluation of the Fear of COVID-19 Scale among Chinese population. (PREPRINT). https://doi.org/10.31234/osf.io/ t5jne

Cheung, G. W., \& Lau, R. S. (2008). Testing mediation and suppression effects of latent variables: Bootstrapping with structural equation models. Organizational Research Methods, 11(2), 296-325

Cheung, F., \& Lucas, R. E. (2015). When does money matter most? Examining the association between income and life satisfaction over the life course. Psychology and Aging, 30(1), 120-135

Dumludag, D. (2013). Life satisfaction and income comparison effects in Turkey. Social Indicators Research, 114(3), 1199-1210

Diener, E. (1984). Subjective well-being. Psychological Bulletin, 95(3), 542-575

Dymond, S., \& Roche, B. (2009). A contemporary behavior analysis of anxiety and avoidance. The Behavior Analyst, 32(1), 7-27

Greenberg, N., Docherty, M., Gnanapragasam, S., \& Wessely, S. (2020). Managing mental health challenges faced by healthcare workers during covid-19 pandemic. The BMJ, 368, m1211

Hsiehchen, D., Espinoza, M., \& Slovic, P. (2020). Political partisanship and mobility restriction during the COVID-19 pandemic. Public Health. https://doi.org/10.1016/j.puhe.2020.08.009

Huarcaya-Victoria, J., Villarreal-Zegarra, D., Podestà, A., \& Luna-Cuadros, M. A. (2020). Psychometric properties of a Spanish version of the Fear of COVID-19 Scale in general population of Lima, Peru. International Journal of Mental Health and Addiction, 1-14. https://doi.org/10.1007/ s11469-020-00354-5

Hu. L, \& Benter. P.M (1998). Fit indices in covariance structure modeling: Sensitivity to underparameterized model misspecification. Psychological Methods, 3(4), 424-453. https://doi.org/10.1037/1082989X.3.4.424.

Labrague, L. J., \& De los Santos, J. (2020). Fear of COVID-19, psychological distress, work satisfaction and turnover intention among front line nurses. (PREPRINT, available at Research Square). https://doi.org/ 10.21203/rs.3.rs-35366/v1

Lang, F. R., Weiss, D., Gerstorf, D., \& Wagner, G. G. (2013). Forecasting life satisfaction across adulthood: Benefits of seeing a dark future? Psychology and Aging, 28(1), 249-261

Leversen, I., Danielsen, A. G., Birkeland, M. S., \& Samdal, O. (2012). Basic psychological need satisfaction in leisure activities and adolescents' life satisfaction. Journal of Youth and Adolescence, 41(12), 1588-1599

Lovibond, S. H., \& Lovibond, P. F. (1995). Manual for the depression anxiety stress scales (2nd ed.). Psychology Foundation

Main, A., Zhou, Q., Ma, Y., Luecken, L. J., \& Liu, X. (2011). Relations of SARS-related stressors and coping to Chinese college students' psychological adjustment during the 2003 Beijing SARS epidemic. Journal of Counseling Psychology, 58(3), 410-423

Mesquita, B., \& Frijda, N. H. (1992). Cultural variations in emotions: A review. Psychological Bulletin, 112(2), 179

Masuyama, A., Shinkawa, H., \& Kubo, T. (2020). Validation and psychometric properties of the Japanese version Fear of COVID-19 Scale among adolescents. International Journal of Mental Health and Addiction. https://doi.org/10.1007/s11469-020-00368-z (Advance online publication)

Mehlsen, M., Thomsen, D. K., Viidik, A., Olesen, F., \& Zachariae, R. (2005). Cognitive processes involved in the evaluation of life satisfaction: Implications for well-being. Aging \& Mental Health, 9(3), 281-290

Mejia, C., Ticona, R., Rodriguez-Alarcon, D., Campos-Urbina, J. F., Catay-Medina, A. M., Porta-Quinto, J. B. ... Tovani-Palone, M. R., P. G. R., \&. (2020). The media and their informative role in the face of the coronavirus disease 2019 (COVID-19): Validation of fear perception and magnitude of the issue (MED-COVID-19). Electronic Journal of General Medicine, 17(6), em239

Moor, I., Spallek, J., \& Richter, M. (2017). Explaining socioeconomic inequalities in self-rated health: A systematic review of the relative contribution of material, psychosocial and behavioural factors. Journal of Epidemiology and Community Health, 71(6), 565-575

Newman, M. G., \& Llera, S. J. (2011). A novel theory of experiential avoidance in generalized anxiety disorder: A review and synthesis of research supporting a contrast avoidance model of worry. Clinical Psychology Review, 31(3), 371-382

Nicola, M., Alsafi, Z., Sohrabi, C., Kerwan, A., Al-Jabir, A., Iosifidis, C. ... Agha, R. (2020). The socioeconomic implications of the coronavirus and COVID-19 pandemic: A review. International Journal of Surgery, 78, 185-193 
Obrien, L. V., Berry, H. L., \& Hogan, A. (2012). The structure of psychological life satisfaction: Insights from farmers and a general community sample in Australia. BMC Public Health, 12(1), 1

Qiu, J., Shen, B., Zhao, M., Wang, Z., Xie, B., \& Xu, Y. (2020). A nationwide survey of psychological distress among Chinese people in the COVID-19 epidemic: Implications and policy recommendations. General Psychiatry, 33(2), e100213

Parady, G., Taniguchi, A., \& Takami, K. (2020). Travel behavior changes during the COVID-19 pandemic in Japan: Analyzing the effects of risk perception and social influence on going-out selfrestriction. Transportation Research Interdisciplinary Perspectives, 7, 100181

Pavot, W., Diener, E., \& Suh, E. (1998). The temporal satisfaction with life scale. Journal of Personality Assessment, 70(2), 340-354

Prenda, Kimberly M.., \& Lachman, Margie E.. (2001). Planning for the future: A life management strategy for increasing control and life satisfaction in adulthood. Psychology and Aging, 16(2), 206216. https://doi.org/10.1037/0882-7974.16.2.206.

Rachman, S. (1994). The overprediction of fear: A review. Behaviour Research and Therapy, 32(7), 683-690

Rachman, S. . (1984).Agoraphobia: A safety-signal perspective. Behaviour Research and Therapy, 22(1), 59-70. https://doi.org/10.1016/0005-7967(84)90033-0.

Rajkumar, R. P. (2020). COVID-19 and mental health: A review of the existing literature. Asian Journal of Psychiatry, 52(March). https://doi.org/10.1016/j.ajp.2020.102066

Read, S., Grundy, E., \& Foverskov, E. (2016). Socio-economic position and subjective health and wellbeing among older people in Europe: A systematic narrative review. Aging and Mental Health, 20(5), 529-542

Reznik, A., Gritsenko, V., Konstantinov, V., Khamenka, N., \& Isralowitz, R. (2020). COVID-19 fear in Eastern Europe: Validation of the Fear of COVID-19 Scale. International Journal of Mental Health and Addiction. https://doi.org/10.1007/s11469-020-00283-3

Ryff, C. D., Kitayama, S., Karasawa, M., Markus, H., Kawakami, N., \& Coe, C. (2018). Survey of Midlife in Japan (MIDJA), April-September 2008. ICPSR30822-v3. Inter-University Consortium for Political and Social Research. https://doi.org/10.3886/ICPSR30822.v3

Roy, D., Tripathy, S., Kar, S. K., Sharma, N., Verma, S. K., \& Kaushal, V. (2020). Study of knowledge, attitude, anxiety \& perceived mental healthcare need in Indian population during COVID-19 pandemic. Asian Journal of Psychiatry, 51(April). https://doi.org/10.1016/j.ajp.2020.102083

Sakib, N., Bhuiyan, A. I., Hossain, S., Al Mamun, F., Hosen, I., Abdullah, A. H. ... Mamun, M. A. (2020). Psychometric validation of the Bangla Fear of COVID-19 Scale: Confirmatory factor analysis and Rasch analysis. International Journal of Mental Health and Addiction. https://doi.org/10. 1007/s11469-020-00289-x

Sasaki, Natsu, Kuroda, Reiko, Tsuno, Kanami, \& Kawakami, Norito. (2020). Exposure to media and fear and worry about COVID-19. Psychiatry and Clinical Neurosciences, 74(9), 501-502. https://doi. org/10.1111/pcn.13095.

Satici, B., Gocet-Tekin, E., Deniz, M. E., \& Satici, S. A. (2020). Adaptation of the Fear of COVID-19 Scale: Its association with psychological distress and life satisfaction in Turkey. International Journal of Mental Health and Addiction. https://doi.org/10.1007/s11469-020-00294-0

Shigemura, J., Ursano, R. J., Morganstein, J. C., Kurosawa, M., \& Benedek, D. M. (2020). Public responses to the novel 2019 coronavirus (2019-nCoV) in Japan: Mental health consequences and target populations. Psychiatry and Clinical Neurosciences, 74(4), 281-282

Shin, D. C., \& Johnson, D. M. (1978). Avowed happiness as an overall assessment of the quality of life. Social Indicators Research, 5(1), 475-492

Sirgy, M. J., Yu, G. B., Lee, D. J., Joshanloo, M., Bosnjak, M., Jiao, J. ... Grzeskowiak, S. (2019). The dual model of materialism: Success versus happiness materialism on present and future life satisfaction. Applied Research in Quality of Life. https://doi.org/10.1007/s11482-019-09763-8

Soraci, P., Ferrari, A., Abbiati, F. A., Del Fante, E., De Pace, R., Urso, A., \& Griffiths, M. D. (2020). Validation and psychometric evaluation of the Italian version of the Fear of COVID-19 Scale. International Journal of Mental Health and Addiction. https://doi.org/10.1007/s11469-020-00277-1

Torales, J., O’Higgins, M., Castaldelli-Maia, J. M., \& Ventriglio, A. (2020). The outbreak of COVID19 coronavirus and its impact on global mental health. International Journal of Social Psychiatry, 66(4), 317-320

Winter, T., Riordan, B. C., Pakpour, A. H., Griffiths, M. D., Mason, A., Poulgrain, J. W., \& Scarf, D. (2020). Evaluation of the English version of the Fear of COVID-19 Scale and its relationship with behavior change and political beliefs. International Journal of Mental Health and Addiction. https://doi.org/10.1007/s11469-020-00342-9 
World Health Organization. (2020). Coronavirus disease (COVID-19) situation reports. https://www.who. int/emergencies/diseases/novel-coronavirus-2019/situation-report

Yıldırım, M., \& Arslan, G. (2020). Exploring the associations between resilience, dispositional hope, preventive behaviours, subjective well-being, and psychological health among adults during early stage of COVID-19. (PREPRINT). https://doi.org/10.31234/osf.io/vpu5q

Zhang, S. X., Wang, Y., Rauch, A., \& Wei, F. (2020). Unprecedented disruption of lives and work: Health, distress and life satisfaction of working adults in China one month into the COVID-19 outbreak. Psychiatry Research, 228, 112958

Publisher's Note Springer Nature remains neutral with regard to jurisdictional claims in published maps and institutional affiliations. 